\title{
POLICÍAS TESTIGOS: AGENTES POLICIALES, TERRITORIO Y PRÁCTICAS JUDICIALES (CIUDAD DE BUENOS AIRES Y ALREDEDORES, DÉCADAS DE 1810 Y 1820) ${ }^{1}$
}

\author{
Policemen as witnesses: Police agents, territory and judicial practices (Buenos \\ Aires city and surroundings, decades of 1810 and 1820)
}

\section{María Agustina Vaccaroni*} https://orcid.org/0000-0002-1006-9322

\section{Resumen}

El interés y la preocupación por un mayor control del territorio impulsaron, desde fines del siglo XVIII, la conformación de nuevas divisiones territoriales en Buenos Aires que fueron acompañadas por el nombramiento de agentes específicos dedicados a su vigilancia. La organización de configuraciones policiales como la Intendencia o el Departamento de Policía, en las décadas de 1810 y 1820 respectivamente, actualizaron el vínculo entre territorio y policía. El conocimiento de los agentes como alcaldes de barrio, tenientes de alcalde y comisarios, sobre los espacios por los que circulaban los residentes y vecinos porteños, los colocó en la posición de testigos en procesos judiciales, en tanto dominaron saberes asociados a los lugares, movimientos y conductas de los acusados y colaboraron así con su identificación. El abordaje de esta problemática en la ciudad de Buenos Aires y sus alrededores, en las décadas que le siguen a la revolución de mayo, demandó la indagación sobre diversos expedientes judiciales que conjugamos con la exploración de las órdenes superiores de la policía y de otros documentos producidos por el gobierno.

$$
<\text { Policía }><\text { Territorio }><\text { Prácticas judiciales }><\text { Testigos }>
$$

\begin{abstract}
Interest and concern for greater territorial control encouraged, from the late 18th century and on, the organization of new territorial divisions in Buenos Aires, which were accompanied by the appointment of specific agents dedicated to their surveillance. The built up of police configurations such as the Intendencia de Policia or the Police Department in the 1810s and 1820s respectively, updated the link between territory and police. The knowledge that agents such as alcaldes de barrio, tenientes de alcalde, and police commissioners acquired on the spaces through which the residents and neighbors circulated placed them in the position of witnesses in judicial processes. They dominated information and were acquainted with places, movements and behaviors of the accused, thus colaborated in their identification. The approach

${ }^{1}$ Las inquietudes volcadas en este artículo forman parte de un estudio más amplio que llevamos adelante en el marco de nuestra tesis doctoral, abocada a analizar las configuraciones policiales desarrolladas entre fines del siglo XVIII y principios del XIX en la ciudad de Buenos Aires, con especial atención a sus funciones, territorialidades y materialidades, bajo la dirección de la Dra. Valeria Ciliberto y el Dr. Agustín Casagrande, y con el financiamiento de una beca de finalización de doctorado otorgada por el CONICET.
\end{abstract}

\footnotetext{
* Becaria posdoctoral del Consejo Nacional de Investigaciones Científicas y Técnicas (CONICET), Instituto de Humanidades y Ciencias Sociales (INHUS-CONICET-UNMDP), Mar del Plata, Argentina, magustinavaccaroni@gmail.com
} 
Vaccaroni. Policías testigos: Agentes policiales, territorio y prácticas judiciales (ciudad de Buenos Aires y...

to this problem in the city of Buenos Aires and its surroundings in the decades that followed the May Revolution demanded an investigation of various judicial files which we combine with the exploration of superior police daily orders and other documents produced by the government.

$<$ Police $><$ Territory $><$ Judicial practices $><$ Witnesses $>$

Recibido: 05/10/2021 //Aceptado: 03/02/2021

\section{Introducción}

En abril de 1811 el alcalde de hermandad de San Nicolás de los Arroyos, Vicente de Mier y Terán, se comunicó con su par de la jurisdicción lindante del pago de los Arroyos, al sur de Santa Fe, con el pedido de elaborar una sumaria sobre Hipólito Jaymes, alias "dos de oro". Decía de Mier sobre el aprehendido por vago que "se me ha informado [que Jaymes] ha residido por el arroyo seco del partido de VM" y que por no existir quien lo conozca en San Nicolás, requería que redactara un parte con "los conocimientos de los sujetos que estén orientados de su conducta". Don Manuel Vidal, el alcalde del mencionado pago de los Arroyos, atendiendo al pedido, recabó información a partir de las declaraciones de varios testigos, que luego fueron enviadas por el propio de Mier a las manos del alcalde de segundo voto del Cabildo de Buenos Aires, Martín Grandoli. El alcalde de San Nicolás señalaba en su pedido inicial que "un vocal de la Excelentísima Junta lo mandaba asegurar [a Jaymes] por ser uno de los miembros que perjudican el cuerpo político". En efecto, las palabras de los testigos corroboraban esta imagen. Uno de ellos refería al "dos de oro" como alguien que no sabe hacer más que "volar por todas partes vagamente", mientras que Don Billaroel, que proveía otro de los testimonios obtenidos, apuntaba que "jamás se conchabo más bien andaba de vago por todas partes"'2.

La lectura del expediente citado pone de manifiesto la importancia adjudicada, por parte de las autoridades y también por parte de los vecinos que actuaban como testigos en el proceso, a los lugares físicos, los espacios y territorios por los cuales se movían y a los cuales estaban vinculados los hombres. Los movimientos parecían ser aceptables mientras estuvieran regulados. Cuando sucedía, como con Jaymes, que circulaba por "todas partes", se producía una asociación inmediata con la vagancia. Por detrás, preocupaban las dificultades para conocer e identificar a estos individuos. Es que en estos momentos de transición dicha identificación estaba atada al territorio y se producía a partir de los conocimientos de vecinos y residentes del espacio en el que se movilizaban las personas. Eran las referencias de los miembros de la propia comunidad las que permitían certezas sobre los habitantes y en especial sobre los acusados de diversos delitos, cuestión fundamental en relación a la carga de la prueba sobre la que descansaba la administración de justicia del período (Yangilevich, 2020, p. 100).

\footnotetext{
${ }^{2}$ Hipólito Jaymes por vago, Archivo Histórico de la Provincia de Buenos Aires (en adelante AHPBA), Fondo Juzgado del Crimen, C. 34, A. 2, L. 33, Exp. 41 (1811). Todas las citas del párrafo corresponden a este expediente. Hemos modernizado la grafía de los documentos utilizados en este trabajo.
} 
Por esto, un mayor control del territorio y por ende de la población formaba parte de las preocupaciones de diferentes autoridades desde fines del siglo XVIII. Para Barriera (2013, p. 44), en esos momentos, se puso en marcha una "verdadera política contra los cuerpos de los hombres sueltos", que alcanzaba, entre otros, al nombrado "dos de oro", finalmente condenado al servicio de armas. En la ciudad, esto se observó no sólo a través de los esfuerzos por organizar la división de la urbe en cuarteles y secciones, sino también con la creación y el nombramiento de figuras institucionales que acumulaban funciones policiales que, en ocasiones, se separaban de las funciones más amplias de gobierno y justicia33. La voz "policía", en este momento, designaba un concepto amplio, correspondiente con el buen orden de la ciudad y se desarrollaba "bajo la forma de reglamentos, obras y creación de jurisdicciones, [...] la policía de fomento y promoción económica, la policía de la moral, policía vial y edilicia, de abastos" (Favelukes, 2007, p. 8). Sus tareas, así planteadas, correspondían al objetivo de conservar la ciudad y a su población en quietud y sosiego, es decir, en armonía, con arreglo a la perspectiva del orden jurídico-político que prevalecía.

La relación entre las configuraciones policiales que se organizaron y el territorio que debían vigilar nos devuelve a ponderar, retomando a Hespanha (1993, p. 88), que la división política del espacio es tanto "un instrumento de poder" como "un 'aparato político' que sirve para organizar y estabilizar el poder de determinados grupos como para desvalijar políticamente a otros". Sobre estos planteos, se han desenvuelto diversos aportes que consideran el vínculo entre el espacio físico, por un lado, y las funciones y agentes policiales, por el otro, aunque para períodos más avanzados del siglo XIX. La tesis de maestría de Gonzalo Iraolagoitia (2014, p. 85), por caso, atiende a las comisarías de la campaña sur de Santa Fe como "unidades espaciales de gobierno" y las considera una "dimensión constitutiva de la espacialidad política provincial". Tanto para él como para Pedro Berardi (2018, p. 25), la policía es un recurso del equipamiento político del territorio -teorizado por Barriera (2009, pp. 45-46)- que se despliega, conjuntamente con las lógicas de estatalidad, en el último tercio del siglo XIX. Este último autor, dedicado al análisis de la conformación de la policía bonaerense desde 1880 a principios del siglo XX, además, ha ahondado sobre las consecuencias de la policía como medio de equipamiento, asociándolo a una profundización de su rol de mediación entre los espacios provinciales en construcción y las autoridades estatales. Por otro lado, también Melina Yangilevich (2018, p. 95), preocupada por el período inmediatamente anterior al tratado por Berardi, advierte las dificultades y negociaciones asociadas a la extensión del poder de policía a través del territorio y a la delimitación de jurisdicciones. A su

\footnotetext{
${ }^{3}$ Funciones y agentes policiales se tradujeron en diversos espacios institucionales que se ensayaron en las décadas que abordamos. A estas experiencias las consideramos y denominamos configuraciones policiales en tanto hablamos de diversos elementos que, en su disposición y forma, hacen a un todo que está en proceso de construcción, que muestra ciertas particularidades orientadas a una intervención y acción sobre el conjunto de la población en vistas a producir un orden determinado o la percepción del mismo, pero que no se muestran como una estructura profesionalizada, especializada y estatalizada. Remitimos a la idea de Moutoukias (2013) quien plantea que lo institucional se organiza mediante "configuraciones dinámicas de individuos interdependientes" y nos proponemos un análisis de las mismas en el terreno, esto es, atendiendo a las funciones y configuraciones de policía como constituidas por relaciones sociales.
} 
Vaccaroni. Policías testigos: Agentes policiales, territorio y prácticas judiciales (ciudad de Buenos Aires y...

vez, los vínculos entre policía y justicia, en la transición desde fines del siglo XVIII a la primera mitad del siglo XIX, han sido analizados por Barreneche (2001) y Casagrande (2019).

Los alcaldes de barrio, tenientes de alcalde y comisarios que analizamos aquí, poco a poco, especificaron sus tareas a partir del espacio que correspondía a su vigilancia. Para ello, sustentaron su acción en configuraciones como la Intendencia de Policía, creada en 1812, y en el Departamento que resultó de la reactualización de la primera, a partir de 1821. Creemos que el fortalecimiento de las nuevas divisiones territoriales ensayadas, así como el nombramiento de agentes específicos que las vigilaran, condujo a una práctica judicial particular que se extendió en el período, a saber, la actuación de alcaldes y comisarios como testigos en los procesos judiciales, sea de manera formal o informal, dando testimonios sobre los espacios de circulación y las conductas de los acusados. Este papel, jugado en la identificación de sujetos y conductas sancionadas, es el que pretendemos analizar en las próximas páginas, primero, abordando el contexto y las dinámicas de construcción de las divisiones espaciales, como cuarteles y secciones, luego, indagando sobre los modos en que los agentes policiales aparecieron, con cierta asiduidad, testimoniando en expedientes judiciales iniciados a partir de robos, heridas y homicidios.

El uso de fuentes judiciales para iluminar aspectos que van más allá de la propia administración de justicia, consecuencia del llamado "redescubrimiento" de estos archivos que comportó originales formas de utilizarlos bajo la orientación de nuevos intereses (Farge, 1991), constituye un insumo fundamental para este trabajo, a los fines de observar las discontinuas formas en que se construyeron las configuraciones policiales del período. A estas fuentes sumamos las propias fuentes producidas por la policía que, como plantea Barreneche (2019, p. 159), proveen una multiplicidad de vías de entradas que están reñidas con la idea de que, de ellas, emana solo un discurso monolítico. La legislación y la documentación de diferentes autoridades como acuerdos del Cabildo y el Registro Oficial de la Provincia de Buenos Aires, entre otros, complementan nuestro análisis, que aborda principalmente las décadas de 1810 y 1820, pero que en momentos se retrotrae a las últimas décadas del siglo XVIII que constituyen un preludio necesario al respecto de las configuraciones policiales porteñas que, en ocasiones, extienden sus prácticas y tareas a los espacios circundantes de la ciudad.

\section{"El cuartel de mi cargo"4. Las configuraciones policiales y el territorio}

Los vínculos entre las divisiones territoriales en la ciudad y sus alrededores, por un lado, y el nombramiento de agentes con funciones policiales, por el otro, resultaron de un ensayo desenvuelto, con más o menos éxito, por parte de la Corona, desde fines del siglo XVIII (Garriga, 2002), que proyectaba un mayor control territorial. En términos locales y para el espacio de Buenos Aires, Sidy (2013, p. 219) constata una cierta capacidad de los idearios borbónicos urbanos para transformar la ciudad, promoviendo

\footnotetext{
${ }^{4}$ María Rosa Acosta por robo de ropa, AHPBA, Fondo Juzgado del Crimen, C. 34, A. 3, L. 53, Exp. 93 (1824).
} 
la circulación, la recolección de impuestos, atendiendo a un mayor control social, pero también económico. Para ello fue fundamental la designación de comisionados y jueces menores destinados a organizar la urbe. Desde aquellas décadas finales del 1700 , existieron variados intentos por organizar configuraciones institucionales de tipo policial, es decir derivadas de una "instancia oeconómica" que planteaba "separarse de la jurisdiccional, pretendiendo simplificar las formas procesales de control de la plebe" (Casagrande, 2019, p. 26). De este modo, la policía se presentó "comme une institution profondément territorialisée; elle exige des divisions de l'espace spécifiques, rationalisées et réfléchies, pour la bonne répartition des forces de police sur l'emseble du territoire urbain" (Marin, 2003, p. 81) . Las palabras de Marin, aunque dedicadas a los cuarteles y la policía de Madrid y Nápoles, bien describen el proceso general que ocurrió en torno a nuestro problema de estudio. La relación entre territorio y policía impactó sobre la potestad derivada de un orden trascendental e indisponible y que, por ello, también entendía al territorio y a su ordenamiento como parte de un esquema natural, principalmente asociado a los lazos de parentesco, solidaridad y vecindad. A partir de múltiples resignificaciones, la imagen neutra y disponible del territorio se fortaleció "con el poder real y con técnicas disciplinarias de control territorial del siglo XVIII” (Agüero, 2018, p. 444).

Las particiones territoriales que se ensayaron y proyectaron, ligándose a la designación de agentes con funciones policiales, fueron diversas. Una primera de ellas estuvo vinculada con los cuarteles en que se fragmentó la ciudad desde $1772^{6}$, y que fueron reconfigurados en múltiples oportunidades hasta los años posteriores a la revolución de mayo. Primero, dieciséis, luego, veinte en $1794^{7}$ y treinta tres, a partir de la década de 1810, los cuarteles se sobreimprimieron sobre otras divisiones que respondían a vínculos de proximidad como las parroquias y barrios ${ }^{8}$. Además del casco urbano en donde funcionaron los cuarteles, existía "una segunda zona urbana con grandes espacios baldíos -que también puede considerarse suburbana- que fue creciendo entre $1810 \mathrm{y}$ 1830, y finalmente un tercer anillo suburbano, ubicado 'extramuros', inmediato y no muy extenso, que combinaba quintas con mataderos, corrales, el cementerio y el puerto del Riachuelo" (Di Meglio, 2006, pp. 28-29). En aquella segunda zona, se erigieron cuarteles suburbanos luego de 1810. Si bien no hemos podido conocer la localización exacta de la Estanzuela de policía, podemos decir que, a partir de ella, la intervención

\footnotetext{
5 "Como una institución profundamente territorializada; requiere divisiones de espacio específicas, racionalizadas y reflexivas para la adecuada distribución de las fuerzas policiales en el territorio urbano". Nos permitimos traducir la cita de Marin para colaborar con la mejor comprensión del problema planteado.

${ }^{6}$ Es posible verificar la propuesta de creación de comisionados / comisarios de manzana junto con la segmentación de la ciudad en cuarteles y breves ensayos de implementación de este esquema que no prosperan en 1734,1747, 1754 y 1766 (Barriera, 2018, p. 140).

${ }^{7}$ El virrey del Río de la Plata, Nicolás de Arredondo, incrementó el número a veinte barrios, organizados luego de la reconversión del proyecto del regente de la audiencia Benito de la Mata Linares que había sido la base para el esquema de cuatro cuarteles (Díaz de Zappia, 2016, pp. 33-34).

${ }^{8}$ A las parroquias de Catedral, Concepción, San Nicolás, Nuestra Señora del Socorro, Monserrat y la Piedad, existentes desde 1769, se sumó San Telmo ya en el siglo XIX, y luego también la división de Catedral, entre sur y norte.
} 
Vaccaroni. Policías testigos: Agentes policiales, territorio y prácticas judiciales (ciudad de Buenos Aires y...

de agentes policiales también alcanzó al anillo extramuros en donde se resguardaban "las bestias de los carros", que utilizaba la policía, y donde se sembraba cebada para alimentarlos. Entonces, a la partición y reorganización territorial, seguía la vigilancia de actores específicamente nombrados para ello.

En términos geográficos, los cuarteles fueron adquiriendo una forma más homogénea, en torno a la cantidad de manzanas que agrupaban a lo largo del tiempo, a la vez que cubrieron una mayor cantidad de las mismas. El agrupamiento de los cuarteles se emparentó con la división pensada por el primer virrey del Río de la Plata, Juan José de Vértiz, al establecer patrullas militares para auxiliar a los alcaldes de barrio, con sus puntos centrales cercanos a las zonas de Concepción, Catedral y Retiro, rodeando la Plaza Mayor ${ }^{10}$. Con el tiempo, integraron áreas ubicadas al oeste de la urbe. Para la década revolucionaria, los cuarteles más populosos eran aquellos emplazados cerca del fuerte y la ribera platense, como los numerados 2, 6, 7 y 9 cuyas poblaciones superaban los dos mil habitantes. Los cuarteles hacia el norte y el sur, en general los más pequeños, concentraban la actividad comercial y también a las familias más adineradas. Si bien se hallaban cerca del límite del casco urbano, estaban cercanos a las rutas de comunicación e "integrados a la ciudad porque su existencia dependía de ella" (Di Meglio, 2006, p. 34). El norte, además, centralizaba cuarteles desde la milicia de caballería, los Húsares y los Granaderos. Los cuatro cuarteles suburbanos, numerados del 30 al 33, estaban bien delimitados y poseían alcaldes y tenientes designados ya en la década de 1810. Estos cuarteles limitarían con la jurisdicción del juzgado de paz de Balvanera, en los años siguientes a 1820. Al sur, la dinámica frontera se confundía con el ámbito de San José de Flores, donde estaban ubicados los cuarteles pertenecientes a la zona denominada como de quintas.

En los primeros años de la década de 1820, a los cuarteles se les sobreimprimió otra partición, la de las comisarías de sección, también llamadas departamentos ${ }^{11}$. Los comisarios que actuaban desde 1812, momento de la creación de la Intendencia de Policía, que desenvolvían su actividad en todos los cuarteles y también en las áreas periurbanas ${ }^{12}$, a partir de 1822 , se nuclearon en estas secciones, desde las cuales debían concretizar su autoridad en una porción expresa de territorio, cuyo centro se encontraba en la oficina -o comisaría- desde donde ejecutaban su acción. La creación de las secciones y de sus comisarías respectivas acompañó la reconfiguración de la Intendencia de Policía en Departamento, al calor de las reformas impulsadas por el

\footnotetext{
${ }^{9}$ Nota del 14 de diciembre de 1819, Archivo General de la Nación (en adelante AGN), Sala X, Multas, carga y data, 32.04.03 (1831-1834-1815).

${ }^{10}$ Instrucción para el buen orden y gobierno de los Alcaldes de Barrio de Buenos Aires, AHPBA, Fondo Real Audiencia - Cámara de Apelaciones, Sección Superintendencia Provincial, C. 7, A. 3, L. 115, Exp. 64 (1790).

${ }^{11}$ Importa destacar que en las nociones de sección y departamento estaba presente el elemento de división, pero atado a una porción o extensión definida donde se ejercía un determinado mando (Real Academia Española, 1817, pp. 285 y 790).

${ }^{12}$ A modo de ejemplo podemos citar la actividad del comisario Felipe Robles que concurre a supervisar la demarcación de Quilmes, hacia donde partió "asociado de Don Francisco Mesura, dos ayudantes de este, y del Escribano Don Manuel José Godoy el 22 de febrero de 1818" (Quesada, 1942, p. 370).
} 
gobernador de Buenos Aires, Martín Rodríguez, y su ministro Bernardino Rivadavia. Como parte de estas iniciativas, la conformación de espacios plausibles de un control más efectivo también se reprodujo, no sin obstáculos, en la campaña cercana. Un ejemplo de lo dicho ocurrió en 1821, con el decreto de división de las jurisdicciones de San Fernando y Las Conchas, otrora pertenecientes a la campaña, y su integración como áreas agregadas a la ciudad ${ }^{13}$. Al mismo tiempo, el gobierno separaba la campaña en departamentos y, en 1823, enviaba ingenieros arquitectos a demarcar los pueblos que se estaban construyendo en ella, bajo la supervisión y previa solicitud frente a los comisarios $^{14}$. Las sucesivas reestructuraciones del territorio en la campaña generaron su partición primero, en tres departamentos, luego, en ocho y, posteriormente, en una política de subdivisión acorde a la necesidad y al ritmo del aumento de la población.

Con cuarteles y secciones se pretendió construir espacios mejor delimitados, con extensiones menores que pudieran ser más fácilmente vigiladas. En la figura I, que corresponde a un plano fechado en 1822 y elaborado por el agrimensor francés Felipe Bertrés, mostramos la división en veintinueve cuarteles, que se mantuvo entre 1812 y el primer lustro de 1820 en la zona urbana, apuntando la cantidad de habitantes de algunos de estos cuarteles. Sobre ellos emplazamos la división en secciones y comisarías que se organiza entre 1822 y 1826 . Esta reconstrucción es aproximada debido a que los documentos y alguna bibliografía sobre el tema aparecen como contradictorios. Para Francisco Romay, comisario retirado y uno de los referentes de la historia oficial de la policía en Argentina, a fines de 1824 las comisarías de ciudad se encontraban delimitadas. Sin embargo, en documentos fechados en 1825, donde se aludía a las disposiciones sobre las comunicaciones entre las comisarías, aún se hacía notar la vacancia en su demarcación que ocurriría finamente en $1826^{15}$.

Si bien la racionalidad al respecto de la división de cuarteles quiso proyectar un espacio decidido, en la práctica este fue, en efecto, construido y experimentado, en cierto modo aprendido. Los límites de los cuarteles siguieron siendo maleables, en tanto la población los percibía de acuerdo a elementos familiares. Por ello, la zona del cuartel 4 era llamada de la Ranchería, mientras que a la zona del cuartel 14 y 1 se la aludía directamente como Retiro -en consonancia con los nombres de los propios barrios-. Otra forma de nombrar los cuarteles -y también las calles- vinculaba espacios con referencias a esquinas o casas conocidas (Di Meglio, 2006, p. 39). En el proceso judicial que inició Benito Vidal por el robo de unas cajas que contenían desde botones hasta navajas de afeitar, sortijas y tijeras, uno de los sospechosos, el albañil José Zapata, declaró que lo prendieron "en la esquina de la casa de Don Juan Agustín Videla"16.

${ }^{13}$ División de la campaña en tres departamentos, 28 de diciembre de 1821 (Registro Oficial de la Provincia de Buenos Aires, 1879, p. 128).

${ }^{14}$ Demarcación de pueblos de campaña, 16 de abril de 1823 (Registro Oficial de la Provincia de Buenos Aires, 1879, p. 28).

${ }^{15}$ Nota del 8 de enero de 1825, AGN, Sala X, Policía, 32.10.5, Libros 12, 13 y 14 (1825).

${ }^{16}$ Causa Criminal sobre la averiguación de los robos hechos a don Benito Vidal de un cajón de efectos y don Francisco José Esteves de 29 pesos en dinero, AHPBA, Fondo Juzgado del Crimen, C. 34, A. 2, L. 34, Exp. 4 (1812). 
Vaccaroni. Policías testigos: Agentes policiales, territorio y prácticas judiciales (ciudad de Buenos Aires y...

Figura I. Mapa de la división del casco urbano de Buenos Aires en veintinueve cuarteles y cuatro secciones, intervenido con datos poblacionales (1812-1826)
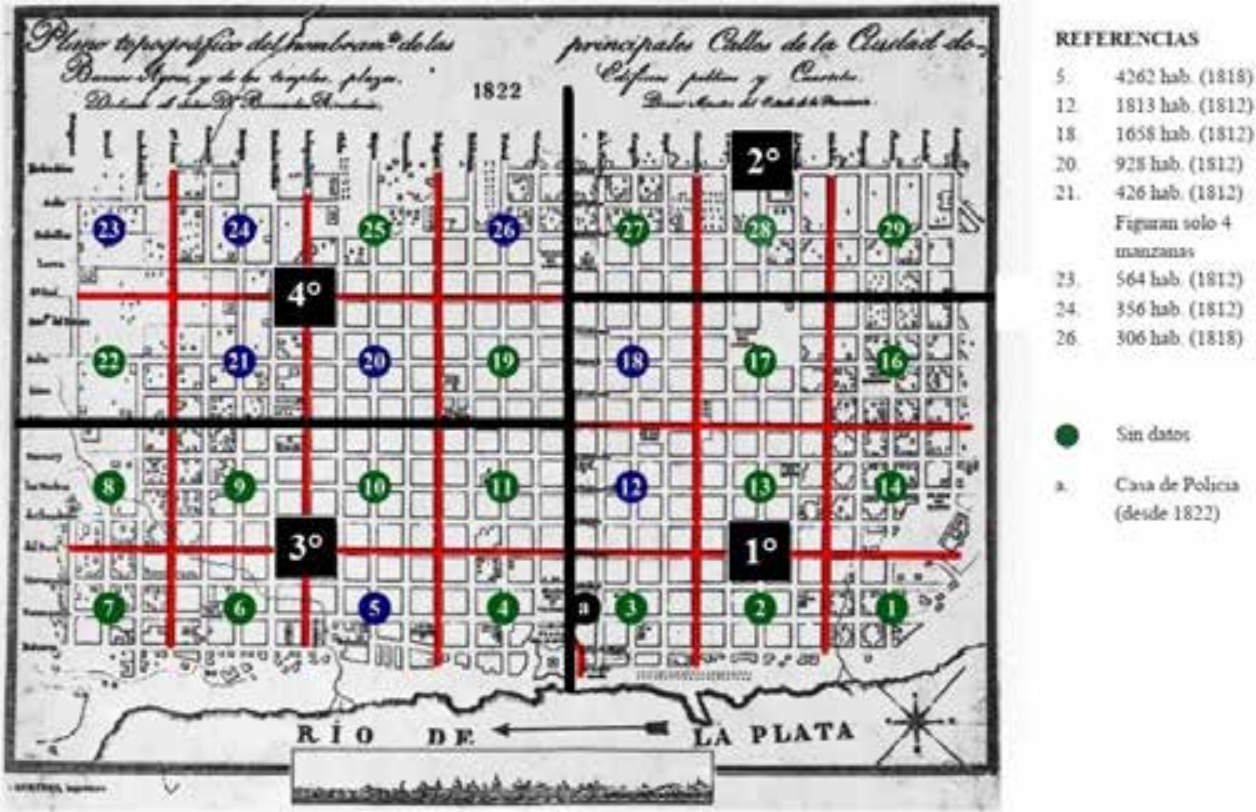

Fuente: Intervención propia sobre plano reproducido en (i) Difrieri (1980, p. 91) con numeración de cuarteles urbanos, división de secciones a partir de datos extraídos del (ii) Registro Oficial de la Provincia de Buenos Aires, años 1821, 1822, 1823, 1824 y 1825 y de (iii) Romay (1979, pp. 225-226), por un lado, y de información demográfica proveniente del (iv) Censo de la Ciudad y Campaña de Buenos Aires contenido en el Padrón 1812-1818, que se encuentra en el AGN, Sala IX, 10.07.02 $2^{17}$.

El proceso de reconocimiento de las nuevas divisiones territoriales fue complejo y los agentes con funciones policiales, nombrados para controlar los "nuevos" espacios, fueron parte de una actualización territorial sobre lugares ya vividos, cuyas inercias también actuaron como un asiento para mejorar los modos de vigilar. El propio alcalde de barrio, que dio parte y realizó la sumaria en el juicio a José Marcos Freda, mencionaba, tanto el número de su cuartel como una esquina conocida, apuntando que "el Alcalde de Barrio del Cuartel $n^{\circ} 3$ da parte a VS que en la esquina pulpería de don Francisco Antonio Bargas y como a las nueve de la noche un portugués llamado José Marcos Ferreyra dio una puñalada mortal a un vizcaíno nombrado don José Arestegui"18. El número del cuartel aparecía más como una alusión a su autoridad y no tanto una ubicación geográfica. Este agente, así, combinaba dos formas de ubicación que yuxtaponían el problema del territorio y la vigilancia. Otro ejemplo de estas referencias

\footnotetext{
${ }^{17}$ Algunos de los cuarteles ubicados en la figura I aparecen sin datos poblacionales debido a que resultó imposible derivar un número exacto del censo, ya fuera por falta de algunas fojas o por los efectos de los años que han generado daños que impiden su correcta lectura.

${ }^{18}$ Criminal contra José Marcos Freda por la muerte que dio a don José Arestegui, AHPBA, Fondo Juzgado del Crimen, C. 34, A. 2, L. 34, Exp.74 (1812).
} 
conocidas podemos encontrarlo en la intervención del propio letrado fiscal, Manuel José Castro, que refería a la zona donde se había cometido un homicidio como "los suburbios de esta capital"19. Al apropiarse de espacios vividos, habitantes y agentes con funciones policiales los transformaron; en muchos casos, las recomendaciones y consideraciones cotidianas sobre los modos de estructurar la ciudad, sus alrededores y los pueblos cercanos fueron atendidas por las autoridades superiores y el gobierno. Tal fue el caso del cuartel 5 que en 1806-1807 contaba con el mayor caudal de población, y que luego de la revolución fue dividido en cuartel 5 y 5 bis, de acuerdo a la sugerencia de Clemente Diez de Medina, intendente de policía en aquel momento, al gobierno, en tanto entendía que dicho cuartel era "muy dilatado y su extensión enerva las providencias ejecutivas que deben tomarse" 20 .

El fraccionamiento espacial no constituyó, en ningún caso, una tarea despojada de tensiones. En el caso de las comisarías, que nucleaban cada vez más agentes con diversas tareas, su delimitación concretizada en el territorio fue dificultosa. Las fronteras de las comisarías habían sido pensadas a la hora de crearlas, como lo prueba una nota firmada por Rivadavia en abril de 1822, que afirma que la distribución de los cuarteles ha sido informada al gobierno ${ }^{21}$. Sin embargo, la efectiva partición se presentó compleja, por lo cual dos años y medio después de aquella primera nota, el propio gobierno insistía, esta vez bajo la firma de Manuel García, sobre esta tarea y encargaba la distribución de cuarteles para cada comisaría al recientemente creado departamento de ingenieros arquitectos. García sumaba una nueva disposición; no sólo debían establecerse límites, sino que cada comisaría debía disponer de un lugar físico de funcionamiento, al modo en que se había logrado con la Casa de Policía. Decía, por lo tanto, que "para facilitar el más exacto cumplimiento en las obligaciones asignadas al Departamento General de Policía [...] el despacho de los comisarios de sección se trasladará al centro de cada una de las cuatro secciones en que se subdivide la ciudad"22, haciéndolo, desde mitad del año 1826, en habitaciones alquiladas con los fondos del Departamento de Policía.

La dilación en la demarcación de las comisarías no impidió que los actores aludidos desarrollaran una actividad dinámica, teniéndolas como núcleo de su actuación y autoridad en forma previa a la delimitación. Por ejemplo, cuando Modesto Sánchez informaba al jefe de policía sobre un robo suscitado en 1823, señalaba que no ha “ocurrido en la sección que está a su cargo más novedad que la prisión hecha por el Alcalde del Cuartel 28 a Pedro Ramírez por haberle robado a Juan Manuel Ruiz cuatro caballos, dos yeguas y la marca"23. Así lo demostraba también el parte hecho a raíz de los excesos cometidos por Anacleto Martínez en el Café de la Victoria, a partir de

\footnotetext{
${ }^{19}$ Criminal: Contra Francisco Luna Por haber muerto a Mariano Salazar en el bajo de la Recoleta, AHPBA, Fondo Juzgado del Crimen, C. 34, A. 2, L. 38, Exp. 46 (1819).

${ }^{20}$ Cabildo del 25 de septiembre de 1813 (Mallié, 1928, p. 654). Esto también sucedía en la campaña. Por ello, en 1826 el comisario de San Nicolás de los Arroyos sugiere al gobierno organizar un nuevo cuartel en su pueblo. Nota del 26 de abril de 1826 (Índice del Departamento General de Policía, 1859, p. 155).

${ }^{21}$ Nota del 10 de abril de 1822, AGN, Sala X, Policía, 32.10.1, Libros 1, 2 y 3 (1812-1822).

${ }^{22}$ Nota del 18 de octubre de 1824, AGN, Sala X, Policía, 32.10.4, Libros 9, 10 y 11 (1824).

${ }^{23}$ Pedro Ramírez por robo, AHPBA, Fondo Juzgado del Crimen, C. 34. A. 3. L.44. Exp. 52, (1823).
} 
Vaccaroni. Policías testigos: Agentes policiales, territorio y prácticas judiciales (ciudad de Buenos Aires y...

los cuales el comisario actuante realizaba un informe haciendo "comparecer en esta comisaría con dos testigos" al detenido ${ }^{24}$. Casi en simultáneo, un proceso similar se verificaba al respecto de los cuarteles. Por caso, en 1819 un alcalde se anoticiaba de la recepción de mil cien velas para el "alumbrado de este cuartel de mi cargo"25. El teniente de alcalde Manuel Ferreyra, al dar parte del proceso iniciado contra Gaspar Pesoa por haberlo desafiado, ubicaba su jurisdicción en el "quartel 9no Manzana 8va"26. Este reconocimiento sucedía en términos más generales también, dando cuenta de espacios reconocidos por una porción mayor de la población. Por ello, en El Argos se publicaban avisos de ventas, alquileres y remates de casas, cuartos y terrenos indicando el número de cuartel y de manzana en los que se encontraban ${ }^{27}$. En el señalamiento del cuartel pesó más la autoridad que emanaba de aquel, en primera instancia, y luego se añadió una dimensión geográfica concreta, como puede observarse cuando el teniente de alcalde del cuartel 28, ya llegando a la mitad de la década de 1820, da parte del robo y venta ilícita de unas prendas, pero se excusa de concurrir a recuperarlas porque no se encontraban en la zona del "cuartel de mi cargo"28.

La multiplicidad de vínculos tejidos entre estos agentes y los vecinos y habitantes, todos ellos atravesados por lo territorial, marcaron un proceso cuyos resultados pueden visualizarse hacia la década de 1820 , cuando los cuarteles y comisarías son efectivas referencias para diversas cuestiones. La identificación entre agentes con funciones policiales y una porción delimitada de territorio que debían vigilar redundó en un mayor discernimiento del terreno y de su población. Esto necesitó de un conocimiento, reflexión y valoración sobre la población a la que se vigilaba y de los cuarteles y comisarías que, con su disposición y límites, fueron utilitarios para este propósito. El pasaje desde un espacio flexible, casi amorfo, sin límites precisos y regulado por ordenanzas reiteradas en torno a la vida cotidiana hacia un espacio que, al menos en términos de proyección, debía mostrarse delimitado y territorializado, impactó en las prácticas de los agentes con funciones policiales y, en particular, en su papel como testigos de las acciones y conductas realizadas por sus vigilados.

\section{"Especificó la calidad de sujetos que son"29. Agentes policiales en la justicia}

Hemos analizado los modos en que se vincularon las particiones territoriales y las configuraciones policiales del período. Conviene ahora volcar la mirada hacia la indagación en torno a las implicancias que estos vínculos suscitaron. En el apartado que

\footnotetext{
${ }^{24}$ Nota del 11 de febrero de 1825, AGN, Sala X, Policía, 32.10.5, Libros 12, 13 y 14 (1825).

${ }^{25}$ Recibo del 26 de julio de 1819, AGN, Sala X, Multas, carga y data 32.04.03 (1831-1834-1815).

${ }^{26}$ Criminal con Gaspar Pesoa por haber desafiado y hecho armas al Teniente Alcalde D. Manuel Ferreyra, AHPBA, Fondo Juzgado del Crimen, C. 34, A.2, L. 38, Exp. 26 (1819).

${ }^{27}$ El Argos de Buenos Aires $n^{\circ}$ 33, 23 de abril de 1823, El Argos de Buenos Aires $n^{\circ}$ 61, del 30 de julio de 1823, y El Argos de Buenos Aires $n^{\circ} 101,17$ de diciembre de 1823 (Junta de Historia y Numismática Argentina, 1939, pp. 135, 251 y 411).

${ }^{28}$ María Rosa Acosta por robo de ropa, AHPBA, Fondo Juzgado del Crimen, C. 34, A. 3, L. 53, Exp. 93 (1824).

${ }^{29}$ Sin carátula, AHPBA, Fondo Juzgado del Crimen, C. 34, A. 2, L. 37, Exp. 19 (1818).
} 
sigue hemos elegido focalizar sobre una de ellas que, consideramos, todavía deja lugar para exámenes más profundos, a saber, la presencia de agentes con funciones policiales testimoniando, formal o informalmente, en los expedientes judiciales, como testigos de los hechos o al respecto de las conductas de los acusados. En efecto, la frase que inicia este acápite es escrita por el comisario Doblas en el juicio que le siguen a tres "agavillados" y forma parte del informe que recoge lo manifestado por el capitán Rafael Alcaraz, al mando de la Compañía de Policía -también llamada partida celadora-, quien reconoce a los acusados. Creemos que esta práctica, que ubica a agentes con funciones policiales testimoniando, pervive en la década posterior a la revolución y es producto del entrelazamiento conflictivo entre policía y territorio en tanto, como sugiere Galeano (2018, p. 71), lo policial constituía "antes que nada, un saber: conocimiento sobre el territorio urbano, sus habitantes y costumbres". Las posibilidades de control e identificación de una población en ascenso tuvieron a las configuraciones policiales y a los agentes involucrados como uno de sus protagonistas. A partir de esto, buscamos añadir al ya analizado y destacado papel de los agentes policiales en la elaboración de sumarios e instrucciones, otra dimensión que los vincula a la administración de justicia, y a la vez, muestra la especificidad que adquiere lentamente la función policial en vínculo con su territorialidad.

Como hemos visto, las divisiones territoriales cobraban un nuevo sentido al nombrar autoridades específicas a cargo de su control y vigilancia. Los alcaldes, que habían sido designados en igual número que los cuarteles existentes desde 1772, sus tenientes de manzana, cuya nominación se generalizó en la década de 1810, y los comisarios de ciudad al frente de cada sección desde 1822, recibían órdenes diversas que los obligaban a recorrer parte de la urbe y a partir de ello, conocerla. Sus funciones incluían tareas de ordenamiento urbano como la organización de la recomposición de los pantanos ${ }^{30}$ y la elaboración de padrones y registros sobre quienes entraban y salían de la capital, sobre los encarcelados, las personas fallecidas, los casamientos y bautismos, los enfermos, los "expósitos" y los alumnos que atendían a las escuelas de primeras letras $^{31}$. También ejecutaban cuestiones de índole política, como celar que los españoles europeos cumplieran con lo dispuesto sobre las salidas nocturnas ${ }^{32}$, hacer circular por la ciudad la proclama de independencia ${ }^{33}$ y transmitir las concurrencias a la Plaza de la Victoria hechas por el gobierno, las convocatorias a las elecciones que se realizaban en las sedes eclesiásticas de sus cuarteles o las citaciones a las tropas ${ }^{34}$.

Con la creación de la Intendencia de Policía en 1812, que absorbió a estos alcaldes, ellos, bien como magistrados de justicia menor, adquirieron funciones de

\footnotetext{
${ }^{30}$ Cabildo del 17 de marzo de 1812 (Mallié, 1928, p. 108).

${ }^{31}$ Razones estadísticas, 11 de diciembre de 1821 ((Registro Oficial de la Provincia de Buenos Aires, 1879 , pp. 105-107).

${ }^{32}$ Cabildo del 5 de julio de 1811 (Mallié, 1927, p. 505).

${ }^{33}$ Cabildo del 16 de agosto de 1816 (Corbet France, 1930, pp. 289-290).

${ }^{34}$ A modo de ejemplo consultar Cabildo del 6 de julio de 1812 (Mallié, 1928, p. 262) y Cabildo del 14 de diciembre de 1821 (Quesada, 1934, p. 561).
} 
Vaccaroni. Policías testigos: Agentes policiales, territorio y prácticas judiciales (ciudad de Buenos Aires y...

vigilancia cada vez más claras ${ }^{35}$. En este mismo año, se nombraron tres comisarios, que en 1821 pasaron a ser cuatro y que, en el transcurso de la década de 1820, se asociaron a comisarías de sección que dividían la ciudad en igual cantidad de departamentos. Los alcaldes de barrio, sus tenientes y los comisarios que formaron parte de las configuraciones policiales en construcción fueron quienes monopolizaron "las fases iniciales de todos los procesos criminales antes de que éstos alcanzaran las manos de un juez" (Barreneche, 2001, p. 18), a través de la conformación de los sumarios e instrucciones, en donde apuntaban los hechos y quiénes eran los acusados.

En relación con la administración de justicia, describir el hecho, señalar testigos y aprehender sospechosos eran tres importantes funciones que alcaldes, tenientes de alcaldes y comisarios realizaban cuando iniciaban los juicios. Barreneche (2001, p. 18) apunta que también dictaban la sentencia al finalizar el proceso. Así, en 1812 el alcalde del cuartel 11, de apellido González, daba parte al intendente de policía de haber "puesto en la cárcel pública la noche del día siete del presente mes a Gregorio Luján por denuncia que tuve de este individuo", al mismo tiempo en que era comisionado a buscar y presentar ante el juez a los denunciantes que habían dado información sobre el acusado ${ }^{36}$. La importancia de estas acciones era tal que cuando los registros y averiguaciones que acompañaban los partes iniciales de los expedientes no se producían o elaboraban, los mismos alcaldes podían ser intimados a hacerlo por alguna de las instancias de la administración de justicia. Por caso, la muerte de Juan Pérez, cazador de la quinta compañía del segundo batallón, aparentemente ejecutada por su propio esclavo ameritó la liberación de una orden al alcalde de barrio correspondiente para que tome conocimiento del hecho, haga las averiguaciones oportunas y, posteriormente, presente los testigos. Junto con esta orden, se advertía a González sobre la posibilidad de un serio apercibimiento "por no haber dado el parte correspondiente según la obligación a que por su cargo está constituida" 37 .

Los saberes y experiencias cotidianas derivadas de la participación de agentes policiales en estas instancias contribuyeron a su papel como testigos en muchos y variados juicios. Alcaldes, comisarios y celadores no sólo buscaban y presentaban a

\footnotetext{
${ }^{35}$ Un recorrido sobre las funciones judiciales y policiales de los alcaldes de barrio puede consultarse en Barriera (2018).

${ }^{36}$ Criminal contra Gregorio y su hermano Luis Luján sobre robos que se le atribuyen por sospecha, AHPBA, Fondo Juzgado del Crimen, C. 34, A. 2, L. 34, Exp. 75 (1812).

${ }^{37}$ Muerte de Juan Pérez por su esclavo, AHPBA. Fondo Juzgado del Crimen, C. 34, A. 2, L. 37, Exp. 9 (1818). No disponemos de información sistematizada al respecto, pero sí podemos señalar que, ante los apercibimientos, amonestaciones y otros castigos, algunos alcaldes se organizaron colectivamente en 1812 contra el propio intendente de policía. Para ello apelaron al Cabildo, explicando cómo la dualidad de órdenes y superioridades a las cuales estaban sujetos podía dificultar su tarea. Así lo consideró Francisco Sagui, alcalde del cuartel 8 quien, junto con otros alcaldes, se presentó ante los capitulares para denunciar la arbitrariedad de la orden de arresto hecha por el intendente contra su persona, argumentando "que noticiosos del lance acaecido por el precitado Sagui, no podían menos de hacer presente al ayuntamiento que de un día a otro estaban expuestos a sufrir iguales sonrojos, y vejámenes por no estar aún deslindadas sus respectivas obligaciones, ni habérseles dado instrucciones que deban servirles de norte en sus procedimientos", Cabildo del 5 de junio de 1812 (Mallié, 1928, pp. 229-230).
} 
los declarantes ante el juez ${ }^{38}$; ellos mismos eran requeridos para cumplir la tarea de testimoniar. A los vecinos y residentes, esos auxiliares informales de la justicia como llama Gabriela Tío Vallejo (2018) que denunciaban a sus colindantes, ahora se sumaba una autoridad policial que podía proveer conocimientos sobre los pobladores, sobre sus lugares de mora, movimiento y circulación ${ }^{39}$.

En muchos expedientes es posible visualizar la intervención de alcaldes y tenientes como lo que podríamos llamar testigos informales; estos actores daban testimonio no en calidad de declarantes, sino al inicio, como parte de los informes que elevaban en los sumarios. En ocasión de la captura y el enjuiciamiento a Bentura Arze, alias Gordillo, tanto un alcalde de hermandad como un teniente de alcalde de barrio actúan como testigos y proveedores de información, cuestión que puede verse en las órdenes e informes que se cruzan entre agentes policiales y judiciales al abrirse el proceso. Antonio Millán, alcalde de hermandad de San José de Flores, informaba en aquella ocasión al vocal de la Cámara de Apelaciones, Francisco del Sar, apuntando que "dicho Gordillo le dice ser compañero en los robos y otros atentados con Leandro Oyola, y Francisco Rodríguez, el Blandengue" y agrega que sabe que "es el mismo que profugó del presidio adonde fue sentenciado por una muerte que hizo en este lugar el año de 1811, [y] ha andado insultando y provocando a varios sujetos de este vecindario". Según Millán, también atacó a su teniente Fernando Visillac que, cuando lo quiso aprehender, fue recibido con una pistola que hirió a su caballo, lo cual permitió el escape de Gordillo.

También en ese expediente encontramos el testimonio del teniente de alcalde Benito Loyza como declarante, señalando que "conoce a Bentura Arze desde pequeño, que en estos últimos años oyó decir que había fugado del presidio; que lo vio en San José de Flores, que estando el declarante de teniente alcalde oyó también que al prenderlo uno de los tenientes de cuartel había hecho resistencia con armas de fuego"40. Es decir que, en el marco de un mismo proceso, es posible encontrar agentes policiales tanto como testigos informales, así como testificando de manera formal, como declarantes. En otro juicio, luego de que el alcalde de barrio apresa al sospechoso "acompañado de dos de mis tenientes" ${ }^{41}$, dichos tenientes se convierten luego en testigos formales.

\footnotetext{
${ }^{38}$ Este tipo de actuación puede observarse en procesos como Criminal contra José Marcos Freda por la muerte que dio a don José Arestegui, C. 34, A. 2, L. 34, Exp.74 (1812), Criminales contra el negro Antonio esclavo de don Marcos Ortega por la muerte que ejecutó en la persona del Capataz de Panadería don Mariano Tpauldo, C. 34, A. 2, L. 36, Exp. 20 (1815) y Criminales contra Juan José Pereira y Manuel ... por haver herido a Candelaria Barrios y querido matar a su marido Pedro Pablo Veroz, C. 34, A. 2, L. 36, Exp. 5 (1815), todos contenidos en el Fondo Juzgado del Crimen del AHPBA.

${ }^{39}$ Los acusados en ocasiones eran atrapados in fraganti por vecinos y policiales actuando en conjunto. A modo de ejemplo, podemos citar cómo algunos vecinos echan por tierra y desarman al negro Antonio y lo retienen frente a una panadería hasta la llegada del alcalde Anselmo Farías, Criminales contra el negro Antonio esclavo de don Marcos Ortega por la muerte que ejecutó en la persona del Capataz de Panadería don Mariano Tpauldo, AHPBA. Fondo Juzgado del Crimen, C. 34, A. 2, L. 36, Exp. 20 (1815).

${ }^{40}$ Criminales contra Bentura Arze prófugo del presidio nombrado Gordillo, AHPBA, Fondo Juzgado del Crimen, C. 34, A. 2, L. 35, Exp. 37 (1813).

${ }^{41}$ Criminales contra Mariano Rojas por robo... Láminas de don Manuel García, AHPBA, Fondo Juzgado del Crimen, C. 34, A. 2, L. 39, Exp. 6 (1820).
} 
Vaccaroni. Policías testigos: Agentes policiales, territorio y prácticas judiciales (ciudad de Buenos Aires y...

Similar situación ocurre en 1817 cuando se hace comparecer al alcalde de barrio del cuartel 14 en el juicio cursado contra el comisario de policía Francisco Doblas. De nombre Matías Sáenz, el alcalde declara que "a principios del presente mes, pasaba el Puente de Barracas en compañía del señor don Juan Ramón Balcarce, y vio dos carros de la Policía inmediatos a la casa dela Quinta que llaman de Gálvez", lugar que el acusado Doblas alquilaba, haciendo uso indebido de los carros de policía para sus operaciones particulares, según la acusación que pesaba sobre él ${ }^{42}$.

El testimonio de Sáenz es requerido como resultado de su actividad de patrullaje, en la cual divisa lo que cree es un delito o, al menos, un manejo irregular de los bienes públicos de la policía. El patrullaje, que a fines del siglo XVIII estaba a cargo de los alcaldes ordinarios y que luego pasan a estar bajo el arreglo de alcaldes, comisarios e intendentes y jefes de policía, permite que estos agentes estén al tanto de los lugares por los cuales se mueven aquellos que consideran peligrosos o donde suele haber una mayor propensión a la comisión de crímenes. Los momentos de mayor agitación política coinciden con la preocupación por ordenar la tarea de patrullaje; así en enero de 1812 se anuncia la institución de la guardia cívica, "un cuerpo respetable de hombres libres, honrados, y beneméritos" a quienes se les confía "la defensa y el sosiego de la capital de las provincias unidas, mientras que los batallones del ejército en el campo del honor destruyen y aniquilan para siempre a los enemigos de la patria" ${ }^{43}$. Aunque no tenemos noticia de la puesta en marcha de esta guardia en los hechos, la discusión al respecto da cuenta de la importancia del control "interno". De nuevo, entre 1820 y 1821, años de acelerados acontecimientos políticos, se discute en el Cabildo un "plan de patrullas y vigilancia de la ciudad en el presente invierno con el objeto de evitar los robos y males que ya se advierten" ${ }^{44}$. La combinación entre patrullar y recorrer el terreno, por un lado, y testimoniar sobre hechos y conductas, consideradas peligrosas en los lugares que los agentes policiales controlan, por el otro, entonces, resulta en una práctica judicial que se extiende en estos años, y que, también, incluirá a los jueces de paz luego de 1821, cuando sean citados a comparecer en diversas ocasiones ${ }^{45}$.

Es que, como plantea Nicolás Duffau (2018, p. 101) para el escenario de la Banda Oriental, la actividad de estos agentes policiales motivó la retroalimentación de redes de información que colaboraron con su tarea. Desde esta perspectiva, se comprende que el alcalde del cuartel 16 Julián Rodríguez, al encontrar un hombre agonizante y

\footnotetext{
${ }^{42}$ Sumaria información seguida por el Sargento Mayor de Voluntarios don Juan José Martínez Jontes, sobre el esclarecimiento del uso indebido de los carros de la Policía con Bueyes de ella, y madera perteneciente al Puente construido de los fondos puestos, por el Comisario de Policía don Francisco Doblas en el camino de la Ensenada", AHPBA, Fondo Real Audiencia - Cámara de Apelaciones, Sección Criminal Provincial, C. 5, A. 5, L. 67, Exp. 15 (1817).

${ }_{43}^{43}$ El superior gobierno al pueblo, El Censor $n^{\circ} 4,28$ de enero de 1812 (Senado de la Nación, 1960, p. 5780).

${ }^{44}$ Cabildo del 12 de junio de 1820 (Quesada, 1934, p. 173). Poco después surgen quejas de los alcaldes de barrio, quienes plantean que, en tanto los vecinos y tenientes están obligados a hacer "guardias en el cuerpo del orden", se niegan a "por lo tanto a prestar el servicio de patrullas", Cabildo del 1 de junio de 1821 (Quesada, 1934, p. 455).

${ }^{45}$ Nota del 26 de enero de 1824, AHPBA, Fondo Real Audiencia - Cámara de Apelaciones, Sección Papeles Sueltos, C. 7, A. 4, L. 9, Exp. 23 (1822).
} 
hacer averiguaciones sobre lo que había pasado, señalaba que, al indagar quién era el malhechor "me dicen" que había sido su hermano ${ }^{46}$.

Los testimonios de los actores con funciones policiales no sólo muestran un conocimiento sobre el terreno y el espacio por el que discurren sospechosos, vagos, mendigos y criminales $-\mathrm{y}$ en ocasiones otros policías-. También ofrecen un panorama de las conductas de los habitantes que vigilan, aquellas que, a través de la voz de comisarios, alcaldes y celadores, es posible reconocer como reprobables. Los agentes policiales dan cuenta del carácter de los acusados y de los querellantes, de su perfil social y económico y, en especial de su reputación, colaborando así para que no hubiera dudas sobre la identidad de los acusados. De este modo, cuando Mariano Chacón era puesto en la cárcel, el alcalde que lo había prendido argumentaba que dicho Chacón era un "hombre malo y perjudicial según los informes que tengo de varios sujetos de probidad de este vecindario". De acuerdo a este alcalde, no sólo era "vago de profesión", sino que también había estado involucrado en un homicidio, conforme los reportes que había obtenido de otro alcalde llamado Pedro Tobal. Uno de sus tenientes, además, afirmaba que cuando el acusado mostró su papeleta de conchabo al capitán de la Compañía de Policía Rafael Alcaraz "pareció ser fingida" 47 . Luego de denunciar a Francisco Rodríguez, sargento del cuerpo de artillería volante, acusado de robar un mate de plata, el sargento comisionado de aquella compañía, Manuel Almada, declaraba contra el acusado, diciendo que "es un hombre haragán sin querer aplicarse otra cosa que al juego, y de continuas quejas de sus malos procedimientos y especialmente en la casa de don Juan Antonio Pereira que se han echado de menos varias cosas en el tiempo que él ha estado viviendo en ella"48. La negra Estefanía Videla era conocida por el alcalde de barrio del cuartel 4, quien señalaba que su apresamiento se había producido "por escandalosa, borracha e insolente y no tener paradero alguno" en enero de 1815, luego de reiteradas advertencias hechas a la mujer a raíz de su comportamiento en las pulperías ${ }^{49}$.

Un esclavo citado como testigo en el juicio contra Antonio Bais ponía de manifiesto cómo se producían estas circulaciones de información en espacios diversos de sociabilidad. Al señalar a Bais como posible autor del robo, argumentaba que sabía que sus conductas incluían jugar a los naipes y evitar el trabajo, y que, a su vez, había oído decir a un teniente de alcalde de barrio "que la noche que se hizo el robo lo había citado para patrullar, y no había asistido" 50 , eludiendo una carga cívica. Por otro lado, Tomás Rodríguez señalaba, en su defensa, que había sido indagado sólo por tener una amistad con otro mozo arrestado por el teniente de barrio Manuel Cándido ${ }^{51}$, es decir,

\footnotetext{
${ }^{46}$ Criminal. Alejandro Arista por haber muerto a su hermano José Arista, AHPBA. Fondo Juzgado del Crimen, C. 34, A. 2, L. 34, Exp. 48 (1812).

${ }^{47}$ Sin carátula, AHPBA, Fondo Juzgado del Crimen, C. 34, A. 2, L. 35, Exp. 67 (1814).

${ }^{48}$ Causa contra Francisco Rodríguez por robo de mate de plata, AHPBA, Fondo Juzgado del Crimen, C. 34, A. 2, L. 33, Exp. 30 (1811).

${ }^{49}$ Criminales contra la negra libre Estefanía Videla, por ebria y escandalosa, AHPBA. Fondo Juzgado del Crimen, C. 34, A. 2, L. 36, Exp. 1 (1815).

${ }^{50}$ Sin carátula, AHPBA, Fondo Juzgado del Crimen, C. 34, A. 2, L. 34, Exp. 58 (1812).

${ }^{51}$ Criminales contra Tomás Rodríguez, AHPBA. Fondo Juzgado del Crimen, C. 34, A. 2, L. 34, Exp. 7 (1812).
} 
Vaccaroni. Policías testigos: Agentes policiales, territorio y prácticas judiciales (ciudad de Buenos Aires y...

por rumores al respecto de confraternidades que se suponían amenazantes. Otro caso es el de Manuel Pérez, empleado de la pulpería de Antonio Butis, quien pedía ante el Cabildo que el alcalde del cuartel 15 "se abstenga de incomodarlo" ya que lo ha obligado a abandonar su puesto en la pulpería por ser español, pero sin tener en cuenta "los notorios servicios que tiene prestados en obsequio a nuestra causa así en la escuadra que se armó al mando del General Brown, como en otros destinos, y últimamente en el que actualmente se halla en la primera Compañía del primer Tercio Cívico" ${ }^{2}$.

La colaboración de los alcaldes, tenientes y comisarios con la administración de justicia, al menos hasta 1830 cuando se anuló por decreto el poder de elaborar los sumarios a los agentes del Departamento de Policía (Gastellu, 2019, p. 101), abarcó diferentes instancias del proceso judicial que incluyeron los partes e informes iniciales, pero también su papel como testigos formales e informales, con todo el peso que ello conllevó en un contexto en donde prevaleció la "justicia de vecinos", un rol principal de la etapa sumarial y las "condiciones de aplicación de la justicia sobre los sujetos a través de la "fama", (Tío Vallejo, 2018, p. 290), esto es a partir de la importancia que se le adjudicaba a la identificación de sujetos a través de la mirada de sus colindantes. La intervención de los agentes policiales, testimoniando en los procesos judiciales, estuvo cimentada en los saberes que estos acumularon en su relación con el territorio y en las interacciones permanentes con subalternos, muchos considerados malentretenidos y escandalosos. Con ello, colaboraron en la identificación de hechos, acusados y conductas no sólo como parte de la comunidad sino también desde una posición de autoridad, que se traslucía en la presentación de los agentes en cuestión como alcaldes de determinados cuarteles, tenientes de manzanas específicas y comisarios de una $\mathrm{u}$ otra sección cuando se presentaban en diferentes momentos del proceso judicial. Esta autoridad, entonces, estaba atada a su nombramiento como agentes de vigilancia sobre una porción del espacio físico de la ciudad y sus alrededores, que se organizó, con marchas y contramarchas, desde fines del siglo XVIII, y con mayor vehemencia en las décadas de 1810 y 1820 que vieron instalarse a la Intendencia y luego al Departamento de Policía.

\section{Reflexiones finales}

La vinculación entre espacio físico y nombramientos de actores destinados a controlarlo se produjo en momentos en que una tensión "recorría las instituciones y que se hacía patente a nivel de gobierno entre iurisdictio y oeconómica, a nivel institucional entre justicia y policía y, a nivel procesal entre proceso y castigo directo" (Casagrande, 2019 , p. 26). Primero por parte de la Corona en su afán por captar una mayor porción de la renta de los territorios de ultramar, y luego por parte de los gobiernos revolucionarios y postrevolucionarios que requerían poner en marcha ciertas trasformaciones y cambios en Buenos Aires, aquella vinculación fue promovida por las necesidades de mejorar la administración territorial.

\footnotetext{
${ }^{52}$ Cabildo del 17 de enero de 1816 (Corbet France, 1930, p. 28).
} 
Las preocupaciones y el interés por atender los lugares donde habitaban o se movían los residentes de una ciudad en crecimiento se visibilizaron en diversos proyectos, con dispar éxito y unos de concreción más celera que otros, de división del territorio. Estas particiones fueron acompañadas por la designación de actores específicos con funciones policiales que auxiliaron a la administración de justicia, pero que también especializaron sus tareas a partir de una concepción simple, rápida y abreviada del proceso (Brondino, 2015) que se derivó de sus tareas de vigilancia en el terreno. La voz de policía, sus funciones de control y vigilancia y las configuraciones que se construyeron en torno a ellas, entonces, adquirieron cierta especificidad que organizó sus tareas a partir del espacio vigilado.

Sobre las iniciativas de partición por parte de las autoridades, los espacios fueron vividos y construidos. Los actores a los que referimos participaron del proceso de apropiación y conversión de los espacios que derivó de las divisiones territoriales implementadas. Al mismo tiempo, las tareas de organización urbana, registros, patrullajes, entre otras, los posicionaron como conocedores del territorio y de sus pobladores. En este proceso, a las nociones de un espacio flexible y a la vez indisponible de acuerdo a un orden jurídico anclado en lo jurisdiccional, se superpusieron iniciativas y experiencias de un espacio delimitado y territorializado, en cuya organización tuvieron un papel destacado los agentes nombrados para vigilarlo.

La asociación entre policía y territorio resultó, a su vez, en una práctica judicial extendida. No sólo en tanto vecinos, sino que, investidos como autoridades policiales, los alcaldes de barrio, sus tenientes de manzana y los comisarios de sección que dependían de la Intendencia y posteriormente del Departamento de Policía, mantuvieron nexos con la administración de justicia, estando presentes en diferentes instancias de los procesos. A la instrucción de sumarios, la formación de partes y el dictamen de sentencias, debemos añadir un elemento que hasta ahora no habíamos advertido con suficiente atención: su papel en la identificación de hechos, conductas y personas consideradas peligrosas, dando cuenta de su reputación, su perfil social y sus relaciones.

A partir de la indagación sobre distintos expedientes, es posible ubicar a estos agentes con funciones policiales actuando en calidad de testigos, en ocasiones sin ser así denominados formalmente, pero proveyendo saberes y conocimientos sobre los acusados. Los testimonios de los agentes policiales conformaron un punto nodal en las posibilidades de aplicación del castigo. La propia Junta de Representantes de Buenos Aires reconocía esto en 1824, al decretar que "no admitirán más pruebas en favor de los sujetos aprehendidos por la policía como vagos, que los informes verbales de los Jueces de Paz o los Alcaldes de barrio"53. Su actuación, como tratamos de mostrar a lo largo de

\footnotetext{
${ }^{53}$ Vagos, 10 de septiembre de 1824 (Registro Oficial de la Provincia de Buenos Aires, 1879, p. 81). Mercedes García Ferrari $(2015$, p. 43) plantea que "si para la policía establecer la identidad individual formaba parte de un conjunto amplio de preocupaciones fuertemente vinculadas al control de un territorio, para los jueces era fundamental, para poder dictar sentencia, confiar en la exactitud de la información sobre los sujetos a quienes impondrían una pena”, es decir que muchos años después del período abordado en este artículo las dinámicas que involucraban a la policía, la justicia, el territorio y la identificación continuaron como problema y preocupación de las autoridades que se ocupaban de controlar a residentes y habitantes de Buenos Aires
} 
Vaccaroni. Policías testigos: Agentes policiales, territorio y prácticas judiciales (ciudad de Buenos Aires y...

este artículo, no se redujo a auxiliares judiciales, sino que expresó la especificidad de la tarea policial en vínculo con un espacio territorializado para su mejor vigilancia y que permitió a estos agentes involucrarse en redes diversas que ofrecían información valiosa que aportaron en sus testimonios.

\section{Fuentes}

Archivo Histórico de la Provincia de Buenos Aires

Fondo Juzgado del Crimen

Causa contra Francisco Rodríguez por robo de mate de plata, C. 34, A. 2, L. 33, Exp. 30 (1811).

Hipólito Jaymes por vago, C. 34, A. 2, L. 33, Exp. 41 (1811).

Causa Criminal sobre la averiguación de los robos hechos a don Benito Vidal de un cajón de efectos y don Francisco José Esteves de 29 pesos en dinero, C. 34, A. 2, L. 34, Exp. 4 (1812).

Sin carátula, C. 34, A. 2, L. 34, Exp. 58 (1812).

Criminales contra Tomás Rodríguez, AHPBA. Fondo Juzgado del Crimen, C. 34, A. 2, L. 34, Exp. 7 (1812).

Criminal contra José Marcos Freda por la muerte que dio a don José Arestegui, C. 34, A. 2, L. 34, Exp.74 (1812).

Criminal contra Gregorio y su hermano Luis Luján sobre robos que se le atribuyen por sospecha, C. 34, A. 2, L. 34, Exp. 75 (1812).

Criminal. Alejandro Arista por haber muerto a su hermano José Arista, C. 34, A. 2, L. 34, Exp. 48 (1812).

Criminales contra Bentura Arze prófugo del presidio nombrado Gordillo, C. 34, A. 2, L. 35, Exp. 37 (1813).

Sin carátula, C. 34, A. 2, L. 35, Exp. 67 (1814).

Criminales contra el negro Antonio esclavo de don Marcos Ortega por la muerte que ejecutó en la persona del Capataz de Panadería don Mariano Tpauldo, C. 34, A. 2, L. 36, Exp. 20 (1815)

Criminales contra Juan José Pereira y Manuel ... por haver herido a Candelaria Barrios y querido matar a su marido Pedro Pablo Veroz, C. 34, A. 2, L. 36, Exp. 5 (1815).

Criminales contra la negra libre Estefanía Videla, por ebria y escandalosa, C. 34, A. 2, L. 36, Exp. 1 (1815).

Muerte de Juan Pérez por su esclavo, C. 34, A. 2, L. 37, Exp. 9 (1818).

Sin carátula, C. 34, A. 2, L. 37, Exp. 19 (1818).

Criminal: Contra Francisco Luna Por haber muerto a Mariano Salazar en el bajo de la Recoleta, C. 34, A. 2, L. 38, Exp. 46 (1819).

Criminal con Gaspar Pesoa por haber desafiado y hecho armas al Teniente Alcalde D. Manuel Ferreyra, C. 34, A.2, L. 38, Exp. 26 (1819).

Criminales contra Mariano Rojas por robo... Láminas de don Manuel García, C. 34, A. 2, L. 39, Exp. 6 (1820). 
Pedro Ramírez por robo, C. 34. A. 3. L.44. Exp. 52, (1823).

María Rosa Acosta por robo de ropa, C. 34, A. 3, L. 53, Exp. 93 (1824).

Fondo Real Audiencia - Cámara de Apelaciones

Instrucción para el buen orden y gobierno de los Alcaldes de Barrio de Buenos Aires, C. 7, A. 3, L. 115, Exp. 64 (1790).

Sumaria información seguida por el Sargento Mayor de Voluntarios don Juan José

Martínez Jontes, sobre el esclarecimiento del uso indebido de los carros de

la Policía con Bueyes de ella, y madera perteneciente al Puente construido de los fondos puestos, por el Comisario de Policía don Francisco Doblas en el camino de la Ensenada, C. 5, A. 5, L. 67, Exp. 15 (1817).

Papeles Sueltos, C. 7, A. 4, L. 9, Exp. 23 (1822).

\section{Archivo General de la Nación}

Sala IX

Censo de la Ciudad y la Campaña de Buenos Aires, 10.07 .02 (1812).

Sala X

Multas, carga y data, 32.04 .03 (1831-1834-1815).

Policía, 32.10.1, Libros 1, 2 y 3 (1812-1822).

Policía, 32.10.4, Libros 9, 10 y 11 (1824).

Policía, 32.10.5, Libros 12, 13 y 14 (1825).

\section{Referencias bibliográficas}

Agüero, A. (2018). "De privilegios fundacionales a constituciones. Territorio y jurisdicción en el origen de las provincias argentinas". En A. Agüero \& R. Diego-Fernández Sotelo (coord.), Jurisdicciones, soberanías, administraciones. Configuración de los espacios políticos en la construcción de los Estados nacionales en Iberoamérica, (pp. 441-480). Córdoba: Universidad Nacional de Córdoba-El Colegio de Michoacán.

Barriera, D. (2009). "Conjura de mancebos. Jurisdicción, equipamiento político del territorio e identidades. Santa Fe del Río de la Plata, 1580”. En D. Barriera (comp.), Justicias y Fronteras. Estudios sobre historia de la Justicia en el Río de la Plata (Siglos XVI-XIX), (pp. 11-49). Murcia: Editum.

Barriera, D. (2013). "Justicias rurales: el oficio de alcalde de la hermandad entre el derecho, la historia y la historiografía (Santa Fe, Gobernación del Río de la Plata, siglos XVII a XIX)". Andes, 24, 17-61. ISSN: 0327-1676.

Barriera, D. (2018). "Y en el principio, fue la justicia. Las alcaldías de barrio: visibilización de un desenredo en la cultura jurisdiccional (de justicia a "policía" y nuevamente a justicia, 1772-1861)". En D. Barriera (dir.), Justicias situadas: entre el Virreinato Rioplatense y la República Argentina 1776-1864, (pp. 129164). La Plata: UNLP-IdIHCS. 
Vaccaroni. Policías testigos: Agentes policiales, territorio y prácticas judiciales (ciudad de Buenos Aires y...

Berardi, P. (2018). Territorialidad, profesionalización y política. La construcción de la policía en la provincia de Buenos Aires, 1880-1916 [Tesis de Doctorado en Historia]. Universidad de San Andrés.

Barreneche, O. (2001). Dentro de la ley, TODO. La justicia criminal de Buenos Aires en la etapa formativa del sistema penal moderno en Argentina. La Plata: Al Margen. Barreneche, O. (2019). De brava a dura. Policía de la Provincia de Buenos Aires. Una historia (1930-1973). Rosario: Prohistoria Ediciones.

Brondino, L. (2015). 'La vía gubernativa: Nascita dell' autoritá amministrativa nel messico ottocentesco?". En D. Generali (coord.), Le radici della razionalitá critica: Sapeeri, pratiche, teleologie. Studi offerti a Fabio Minazzi, (pp. 10191027). Milán: Mímesis.

Casagrande, A. (2019). Gobierno de justicia, poder de policía. La construcción oeconómica del orden social en Buenos Aires (1776-1829). Valencia: Tirant.

Corbet France, E. (1930). Acuerdos del Extinguido Cabildo de Buenos Aires. Tomo VII, Libros LXXIV a LXXIX, Serie IV, años 1816 a 1817. Buenos Aires: Kraft.

Corbet France, E. (1930). Acuerdos del Extinguido Cabildo de Buenos Aires. Buenos Aires: Kraft, Tomo VII, Libros LXXIV a LXXIX, Serie IV, años 1816 a 1817.

Díaz de Zappia, S. (2016). Conduciendo el orden y la felicidad pública: los alcaldes de barrio de la ciudad de Buenos Aires (1772-1821) [Tesis de Doctorado en Historia no publicada]. Universidad del Salvador.

Difrieri, H. (1980). Atlas de Buenos Aires. Tomo II. Mapas y Planos. Buenos Aires: MCBA-Secretaría de Cultura.

Di Meglio, G. (2006). ¡Viva el bajo pueblo! La plebe de Buenos Aires y la política entre la Revolución de Mayo y el Rosismo (1810-1829). Buenos Aires: Prometeo.

Duffau, N. (2018). "La policía en la provincia oriental (1826-1838). Una construcción institucional entre el Antiguo Régimen y el orden republicano". Anuario IEHS, 33, 85-105. ISSN: 2524-9339.

Farge, A. (1991). La atracción del archivo. Valencia: Edicions Alfons el Magnànim-IVEI.

Favelukes, G. (2007). 'Para mejor orden y policía de la ciudad'. Reformas borbónicas y gobierno urbano en Buenos Aires. Seminario Crítica IAA. Recuperado de: http:// www.iaa.fadu.uba.ar/publicaciones/critica/0158.pdf

Galeano, D. (2018). Delincuentes viajeros. Estafadores, punguistas y policías en el Atlántico sudamericano. Buenos Aires: Siglo XXI editores.

García Ferrari, M. (2015). "Una aproximación a las relaciones entre identificación y justicia en Argentina (1886-1933)". Estudios Sociales, 48, 39-58. ISSN: 0327-4934.

Gastellu, S. (2019). "Una justicia para el gobierno local: Los jueces de paz de la ciudad de Buenos Aires (1821-1826). Revista de Historia del Derecho, 58, 79125. ISSN: $1853-1784$.

Hespanha, A. M. (1993). La Gracia del derecho. Economía de la cultura en la Edad Moderna. Madrid: Centro de Estudios Constitucionales.

Índice del Departamento General de Policía (1859). Buenos Aires: Imprenta La Tribuna. Iraolagoitia, G. (2014). Territorio, autoridad y Estado: comisarías de distrito y juzgados de paz en la campaña sur santafesina, 1854-1883 [Tesis de Maestría en Historia no publicada]. Universidad de San Andrés. 
Junta de Historia y Numismática Americana (1915). La Gaceta de Buenos Aires, reimpresión facsimilar (1810-1821). Buenos Aires: Compañía Sudamericana de Billetes de Banco.

Junta de Historia y Numismática Argentina (1939). El Argos de Buenos Aires, reimpresión facsimilar. Buenos Aires: Atelier de Artes Gráficas Futura.

Mallié, A. (1927) Acuerdos del Extinguido Cabildo de Buenos Aires. Tomo IV, Libros LXV a LXVII, Serie IV, años 1810 a 1811. Buenos Aires: Kraft

Mallié, A. (1928). Acuerdos del Extinguido Cabildo de Buenos Aires. Tomo V, Libros LXVII a LXIX, Serie IV, años 1812 a 1813. Buenos Aires: Kraft.

Marin, B. (2003). "Les polices royales de Madrid et de Naples et les divisions du territoire urbain (fin XVIIIe-début XIXe siècle)". Revue d'histoire moderne et contemporaine, 50, 81-103. ISSN: 0048-8003.

Moutoukias, Z. (2013). 'Des liens sociaux à l'ordre politique: réflexions pour une approche relationnelle des institutions". Caravelle, 101, 111-132. ISSN: 2272-9828.

Quesada, H. (1934). Acuerdos del Extinguido Cabildo de Buenos Aires. Tomo IX. Libros LXXXIII a LXXXVIII, Serie IV, años 1820 a 1821. Buenos Aires: Kraft

Real Academia Española (1817) Diccionario de la lengua castellana. Madrid: Imprenta Real. Recuperado de http://ntlle.rae.es/ntlle/SrvltGUILoginNtlle.

Registro Oficial de la Provincia de Buenos Aires, año 1821 (1879). Buenos Aires: Imprenta de José y Luis Rossi.

Registro Oficial de la Provincia de Buenos Aires, año 1823 (1879). Buenos Aires: Imprenta de José y Luis Rossi.

Registro Oficial de la Provincia de Buenos Aires, año 1824 (1879). Buenos Aires: Imprenta de José y Luis Rossi.

Romay, F. (1979). Historia de la policía federal argentina. Tomo II. Buenos Aires: Editorial Policial.

Senado de la Nación (1960). Biblioteca de Mayo. Colección de obras y documentos para la Historia Argentina. Tomo VIII: Periodismo. Buenos Aires: Comisión de educación del Honorable Senado.

Sidy, B. (2013). "Proyectos urbanos en disputa: los debates en torno al proyecto de la Alameda en Buenos Aires (1766-1768)". Antiteses, 12, 217-238. ISSN: 1984-3356.

Tío Vallejo, G. (2018). "La voz de los vecinos en el momento del sumario. Testigos y auxiliares de la justicia en casos de la ciudad y la campaña tucumanas entre 1820 y 1850”. En D. Barriera (dir.), Justicias situadas: entre el Virreinato Rioplatense y la República Argentina 1776-1864, (pp. 289-316). La Plata: UNLP-IdIHCS.

Yangilevich, M. (2020). "De las filiaciones a la fotografía. El problema de la identificación de acusados, procesados y condenados (Provincia de Buenos Aires, Argentina, segunda mitad del siglo XIX)"'. En J. Nuñez \& P. Vacani (dir.), El castigo en la conformación de los saberes penales y penintenciarios: racionalidades, instituciones y tratos punitivos en la Argentina. Siglos XIX-XXI, (pp. 99-120). Buenos Aires: Ediciones del Sur.

Yangilevich, M. (2018). "Prefecturas, comisarías de campaña y construcción estatal en la Provincia de Buenos Aires (Argentina) a mediados del siglo XIX”. Secuencia, 102, 70-99. ISSN: 0186-0348. 